\title{
Clinical utility gene card for: CHARGE syndrome - update 2015
}

\author{
Conny MA van Ravenswaaij-Arts ${ }^{\star,}$, Kim Blake $^{2}$, Lies Hoefsloot ${ }^{3}$ and Alain Verloes ${ }^{4}$ \\ European Journal of Human Genetics (2015) 23, doi:10.1038/ejhg.2015.15; published online 18 February 2015
}

Update to: European Journal of Human Genetics (2011) 19, doi:10.1038/ejhg.2011.45; published online 16 March 2011

\section{DISEASE CHARACTERISTICS}

1.1 Name of the disease (synonyms)

CHARGE syndrome (CHARGE association, Hall-Hittner syndrome).

\subsection{OMIM\# of the disease}

214800 .

1.3 Name of the analyzed genes or DNA/chromosome segments CHD7.

\subsection{OMIM\# of the gene(s)}

608892 .

\subsection{Mutational spectrum}

Predominantly heterozygous single-nucleotide variants which affect protein function ( $44 \%$ nonsense, $34 \%$ frame shift, $11 \%$ splice site and $8 \%$ missense). Less than $5 \%$ whole-exon deletions or microdeletions of 8q12.1 including CHD7 (http://www.chd7.org/). ${ }^{1}$

\subsection{Analytical methods}

Sequencing of all coding exons, including their boundaries of CDH7 by Sanger sequencing, as part of a targeted gene panel for Mendelian syndromes, or by whole-exome sequencing. ${ }^{2}$ MLPA covering most coding exons, including the 5'UTR and the first non-coding exon of CHD7. ${ }^{3}$ Array CGH in selected cases. ${ }^{4}$ Conventional cytogenetics is usually normal. Translocations with breakpoint through CHD7 have been reported incidentally. ${ }^{1}$

\subsection{Analytical validation}

Sequence analysis detects $>99 \%$ of the (single) nucleotide variants present in the area that has been investigated. For parallel sequencing techniques the false negative rate depends on the coverage of the gene with the panel or platform used. MLPA has an estimated sensitivity of $>90 \%$ for individual exons, and $>95 \%$ for deletions covering more probes.

1.8 Estimated frequency of the disease (Incidence at birth ('birth prevalence') or population prevalence)

Prevalence at birth $=1: 15000-17000{ }^{1}$
1.9 If applicable, prevalence in the ethnic group of the investigated person

There is no evidence at present for a different prevalence in various ethnic groups.

1.10 Diagnostic setting

\begin{tabular}{lll}
\hline & Yes & No \\
A. (Differential) diagnostics & $\bigotimes$ & $\square$ \\
B. Predictive testing & $\square$ & $\square$ \\
C. Risk assessment in relatives & $\square$ & $\square$ \\
D. Prenatal & $\square$ & $\square$
\end{tabular}

Comment:

Not applicable.

\section{TEST CHARACTERISTICS}

2.1 Analytical sensitivity

(proportion of positive tests if the genotype is present)

\begin{tabular}{|c|c|c|c|c|}
\hline & \multicolumn{2}{|c|}{ Genotype or disease } & \multirow{2}{*}{$\begin{array}{l}\text { A: True positives } \\
\text { B: False positives }\end{array}$} & \multirow{2}{*}{$\begin{array}{l}\text { C: False negative } \\
\text { D: True negative }\end{array}$} \\
\hline & Present & Absent & & \\
\hline \multicolumn{5}{|l|}{ Test } \\
\hline Positive & A & $\mathrm{B}$ & $\begin{array}{l}\text { Sensitivity: } \\
\text { Specificity: }\end{array}$ & $\begin{array}{l}A /(A+C) \\
D /(D+B)\end{array}$ \\
\hline Negative & $\mathrm{C}$ & $\mathrm{D}$ & $\begin{array}{l}\text { Positive predictive value: } \\
\text { Negative predictive value: }\end{array}$ & $\begin{array}{l}A /(A+B) \\
D /(C+D)\end{array}$ \\
\hline
\end{tabular}

Depends on the method used. If only CHD7 sequencing is performed, deletions are missed. In $<5 \%$ of the patients, CHARGE syndrome is due to whole-exon or whole-gene deletions. ${ }^{3,5}$ If Sanger sequencing is combined with MLPA, the sensitivity is almost $100 \%$. For parallel sequencing techniques the analytical sensitivity depends on the coverage of the gene in the panel or platform used.

\footnotetext{
${ }^{1}$ University of Groningen, University Medical Centre Groningen, Department of Genetics, Groningen, The Netherlands; ${ }^{2}$ Department of Pediatrics, IWK Health Centre, Dalhouse University, Halifax, Nova Scotia, Canada; ${ }^{3}$ Department of Clinical Genetics, Erasmus MC, Rotterdam, The Netherlands; ${ }^{4}$ Department of Medical Genetics, APHP-Robert DEBRE University Hospital, Paris, France

*Correspondence: Professor CMA van Ravenswaaij-Arts, University of Groningen, University Medical Centre Groningen, Department of Genetics, PO Box 30.001 , Groningen 9700 RB, The Netherlands. Tel: +31 50 3617229; Fax: +31 50 3617231; E-mail: c.m.a.van.ravenswaaij@umcg.nl
}

Received 15 September 2014; revised 5 December 2014; accepted 13 January 2015; published online 18 February 2015 
2.2 Analytical specificity

(proportion of negative tests if the genotype is not present)

The analytical specificity is almost $100 \%$. Some variants may be erroneously interpreted as disease-causing. An interpretation algorithm for missense variants has been published by Bergman et al. ${ }^{6}$

\subsection{Clinical sensitivity}

(proportion of positive tests if the disease is present)

The clinical sensitivity can be dependent on variable factors such as age or family history. In such cases a general statement should be given, even if quantification can only be made case-by-case.

The clinical sensitivity depends on the clinical criteria used. In over $90 \%$ of the patients who fulfill the criteria of Blake et al. ${ }^{7}$ or Verloes et al., ${ }^{8}$ a disease-causing variant is found. ${ }^{9}$ In those who are suspected for CHARGE syndrome, in $30-60 \%$, a disease-causing variant is found. ${ }^{1,10}$ CHARGE syndrome often can be excluded if a patient does not fulfill the clinical criteria and does not carry a disease-causing variant or deletion of CHD7.

The clinical variability of the syndrome is considerable. If the diagnosis is based on the Blake et al. ${ }^{7}$ or Verloes et al. ${ }^{8}$ criteria, some people with CHARGE syndrome will be missed. The clinical specificity of these criteria is $\sim 85 \%$, as $14-17 \%$ of the patients with a CHD7 disease-causing variant do not completely fulfill these criteria. ${ }^{4}$ Bergman et al. ${ }^{6}$ defined criteria for CHD7 testing and showed that if these criteria were used the risk of not offering the test to a patient with a $\mathrm{CHD} 7$ disease-causing variant was extremely low. ${ }^{4}$ But, it should be taken into account that the mild end of the phenotypic spectrum is still expanding. Note that some patients with CHD7 mutations also fit a diagnosis of Kallmann syndrome. At the mildest end of the phenotypic spectrum, patients with CHD7 disease-causing variants may show hypogonadotropic hypogonadism with some additional minor features of CHARGE syndrome. ${ }^{11-13}$

Some conditions can mimic CHARGE syndrome: 22q11.2 deletion syndrome, VACTERL association, SOX2 mutations, mandibulofacial dysostosis, chromosomal disorders (eg, deletions 3p12p21.2), ${ }^{14}$ disorders caused by teratogens (eg, maternal diabetes, Accutane) and Kallmann syndrome. ${ }^{13}$

\subsection{Clinical specificity}

(proportion of negative tests if the disease is not present)

The clinical specificity can be dependent on variable factors such as age or family history. In such cases a general statement should be given, even if a quantification can only be made case-by-case.

If the disease is not present no disease-causing CHD7 variants will be found, and thus in theory the clinical specificity is $100 \%$. However, the interpretation of missense variants can be complicated. Bergman et al. ${ }^{6}$ has published a guideline for the interpretation of CHD7 missense variants. See also the public database with the CHD7 variants and their classification available at: http://www.chd7.org/.

\subsection{Positive clinical predictive value (life-time risk of developing the} disease if the test is positive)

Estimated $100 \%$, but high clinical variability. The penetrance of pathogenic CHD7 variants is complete: truly asymptomatic carriers of known disease-causing variants have not been reported, but expressivity may be subtle and the diagnosis may be overlooked in atypical cases.
2.6 Negative clinical predictive value (probability of not developing the disease if the test is negative)

Assume an increased risk based on family history for a non-affected person. Allelic and locus heterogeneity may need to be considered.

Index case in that family had been tested:

$100 \%$

Index case in that family had not been tested:

This depends on the a priori chance of the index carrying a disease-causing variant: this varies between 60 to $90 \%$. There is always a residual risk, but complete analysis (sequencing and MLPA) will reduce the chance that the proband carries a diseasecausing variant which cannot be detected by current techniques by 90-95\%.

\section{CLINICAL UTILITY}

3.1 (Differential) diagnostics: The tested person is clinically affected (To be answered if in 1.9 'A' was marked)

\subsubsection{Can a diagnosis be made other than through a genetic test?}

\begin{tabular}{lll}
\hline No (continue with 3.1.4) & $\square$ & \\
Yes & $\square$ & $\square$ \\
& Clinically & \\
& Imaging & \\
& & olfactory bulbs) \\
& Endoscopy & $\square$ \\
& Biochemistry & $\square$ \\
& Electrophysiology & $\square$ \\
& Other (please describe) & endocrine investigations
\end{tabular}

\subsubsection{Describe the burden of alternative diagnostic methods to the} patient

CHARGE syndrome can be diagnosed clinically but not solely by using the CHARGE acronym $(\mathrm{C}=$ coloboma, $\mathrm{H}=$ heart defect, $\mathrm{A}=$ choanael Atresia, $\mathrm{R}=$ retardation of growth and development, and $\mathrm{E}=$ ear abnormalities) or the major criteria (coloboma of the eyes, choanal atresia, characteristic ear malformations including deafness, arhinencephaly and cranial nerve abnormalities). Scanning of the temporal bones often elicits abnormalities in the semi-circular canals which brings more specificity to the diagnosis.

This implies that for a clinical diagnosis the following clinical investigations usually are performed: ophthalmoscopy, cardiac and renal ultrasound, cranial CT and cerebral MRI (with fine cuts over temporal bones and olfactory bulbs), audiometry and other cranial nerve testing (ie, swallowing studies).

\subsubsection{How is the cost effectiveness of alternative diagnostic methods to be judged?}

Gene testing is still expensive, and for that reason many parents, particularly those with older children, have not had their child tested. ${ }^{15}$ Either gene testing or clinical criteria can miss some individuals with CHARGE syndrome. However, gene testing may be important in patients who do not have the classical CHARGE characteristics and may be at-risk for the long-term complications of CHARGE syndrome.

Gene testing is important for recurrence risk and reproductive options. 
3.1.4 Will disease management be influenced by the result of a genetic test?

\begin{tabular}{ll}
\hline No $\quad$ & $\square$ \\
Yes & $\bigotimes$ as long-term \\
& complications may \\
be anticipated \\
Therapy (please \\
describe)
\end{tabular}

Prognosis (please describe)

Management (please describe) calcium are required). ${ }^{16}$ prognosis. Parents are also required to be highly management.
Depends on clinical manifestations: severe gastroesophageal reflux resulting in tube feeding, problems with swallowing and aspiration, and secretions are a cluster of the hidden problems in CHARGE syndrome. An early diagnosis enables earlier identification of hearing and visual loss and surveillance within a multidisciplinary educational team, physiotherapy, occupational therapy, speech therapy and psychology. Some patients require growth hormone and many require hormones to enter puberty. Problems with bone mineral density means nutritional therapy and physiotherapy, early in life and into adolescence (increased levels of vitamin $D$ and

Prognosis is highly variable, including absent to severe intellectual disability, and challenging behaviors. Many patients have sensory impairment, including both vision and auditory deficits. An early diagnosis and management of the sensory impairments may improve proactive and organized with this syndrome involving such complexity. There is a high mortality and morbidity from anesthesia. Parents and patients can join the international CHARGE Syndrome Foundation. This can be divided into early, middle and late

Early management may involve repair of choanal atresia, cardiac abnormalities and tracheoesophageal fistula. Attention to gastroesophageal reflux and the swallowing mechanism is an important early management problem that is often forgotten. ${ }^{4,17}$ Botox injections into the salivary glands have recently been proven to be effective. ${ }^{18}$

Middle management should pay attention to physical therapy for balance problems, occupational therapy for fine motor and feeding problems, and speech and language therapy for swallowing, feeding problems and speech. Furthermore, watching for hidden anomalies such as renal disease, immunological dysfunction, and continued assessment of hearing and vision with a view to bone-anchored hearing aids or cochlear implants should be offered. ${ }^{17}$ Sleep apnea presents as night-time snoring and apneas should be investigated by sleep studies and ENT referral. ${ }^{19}$ Consider partial or complete removal of tonsils and adenoids.

Late management should include endocrine investigation as hormone issues are common. Growth hormone deficiency is less prevalent than abnormalities of gonadotropic hormones, especially in boys. ${ }^{20}$ Vitamin $\mathrm{D}$ and calcium intake throughout childhood and into adolescence needs to be maximized. We recommend increased calcium and vitamin D intake to protect bone development, as well as weight-bearing exercises. ${ }^{16}$ In later life watch out for obesity.
3.2 Predictive Setting: The tested person is clinically unaffected but carries an increased risk based on family history

(To be answered if in 1.9 'B' was marked)

\subsubsection{Will the result of a genetic test influence lifestyle and prevention?}

If the test result is positive (please describe) Yes, see 3.1.4.

If the test result is negative (please describe) Depends on the clinical manifestations.

3.2.2 Which options in view of lifestyle and prevention does a person at-risk have if no genetic test has been done?

No special options.

3.3 Genetic risk assessment in family members of a diseased person (To be answered if in 1.9 'C' was marked)

\subsubsection{Does the result of a genetic test resolve the genetic situation in that family?}

Not necessarily, but if a disease-causing variant is found in the patient and not in the parents, recurrence risk can be given with more certainty and prenatal diagnosis can be offered. Moreover, in that situation, siblings of the patient do not have an increased risk for children with CHARGE syndrome. If the disease-causing variant is found in mosaic or non-mosaic form in one of the parents, recurrence risk is increased (up to 50\%) and prenatal or pre-implantation diagnosis should be discussed.

3.3.2 Can a genetic test in the index patient save genetic or other tests in family members?

Family members may have very mild characteristics of CHARGE syndrome and somatic mosaicism has been described in parents. Therefore, parents of an apparently sporadic case should always be tested when wishing for another child, to obtain a more accurate recurrence risk.

3.3.3 Does a positive genetic test result in the index patient enable a predictive test in a family member?

Yes, theoretically. As penetrance of $\mathrm{CHD} 7$ pathogenic variants is almost $100 \%$ when minor signs are searched for, predictive test would be a rare issue.

\subsection{Prenatal diagnosis}

(To be answered if in 1.9 ' $\mathrm{D}$ ' was marked)

\subsubsection{Does a positive genetic test result in the index patient enable a} prenatal diagnosis?

Yes. If an index patient has CHARGE syndrome, then subsequent pregnancies can be screened genetically and by fetal ultrasound and eventually by fetal MRI.

\section{IF APPLICABLE, FURTHER CONSEQUENCES OF TESTING}

Please assume that the result of a genetic test has no immediate medical consequences. Is there any evidence that a genetic test is nevertheless useful for the patient or his/her relatives? (Please describe).

There is a lot of discussion in Hartshorne et al. ${ }^{15}$ that might be helpful, including reasons for testing or not testing given by parents and a discussion of the ethical issues involved. 


\section{CONFLICT OF INTEREST}

The authors declare no conflict of interest.

1 Janssen N, Bergman JE, Swertz MA et al: Mutation update on the CHD7 gene involved in CHARGE syndrome. Hum Mutat 2012; 33: 1149-1160.

2 Vissers LE, van Ravenswaaij CMA, Admiraal $\mathrm{R}$ et al: Mutations in a new member of the chromodomain gene family cause CHARGE syndrome. Nat Genet 2004; 36: 955-957.

3 Bergman JEH, de Wijs I, Hoefsloot LH, Jongmans MCJ, van Ravenswaaij CMA: Exon copy number alterations of the $\mathrm{CHD7}$ gene are not a major cause of CHARGE syndrome. Eur J Med Genet 2008; 51: 417-425.

4 Bergman JEH, Janssen N, Jongmans M, Hoefsloot LH, van Ravenswaaij-Arts CMA CHD7 mutations and CHARGE syndrome: the clinical implications of an expanding phenotype. J Med Genet 2011; 48: 334-342.

5 Wincent J, Schulze A, Schoumans J: Detection of CHD7 deletions by MLPA in CHARGE syndrome patients with a less typical phenotype. Eur J Med Genet 2009; 52 271-272.

6 Bergman JE, Janssen N, van der Sloot AM et al: A novel classification system to predict the pathogenic effects of CHD7 missense variants in CHARGE syndrome. Hum Mutat 2012; 33: 1251-1260.

7 Blake KD, Davenport SLH, Hall BD et al: CHARGE association: an update and review for the primary pediatrician. Clin Genet 1998; 37: 159-173.

8 Verloes A: Updated diagnostic criteria for CHARGE syndrome; a proposal. Am J Med Genet 2005; 133A: 306-308.

9 Jongmans MC, Admiraal RJ, van der Donk KP et al: CHARGE syndrome: the phenotypic spectrum of mutations in the CHD7 gene. J Med Genet 2006; 43: 306-314.
10 Bartels CF, Scacheri C, White L, Scacheri PC, Bale S: Mutations in the CHD7 gene: the experience of a commercial laboratory. Genet Test Mol Biomarkers 2010; 14 881-891.

11 Kim HG, Kurth I, Lan F et al: Mutations in CHD7, encoding a chromatin-remodelling protein, cause idiopathic hypogonadotropic hypogonadism and Kallmann syndrome. Am J Hum Genet 2008; 83: 511-519.

12 Jongmans MCJ, Ogata T, Sato $\mathrm{N}$ et al: CHD7 mutations in patients initially diagnosed with Kallmann Syndrome - the clinical overlap with CHARGE syndrome. Clin Genet 2009; 75: 65-71.

13 Bergman JEH, de Ronde W, Jongmans MCJ et al: The results of CHD7 analysis in clinically well-characterized patients with Kallmann syndrome. J Clin Endocrinol Metab 2012; 97: E858-E862.

14 Wieczorek D, Bolt J, Schwechheimer K, Gillessen-Kaesbach G: A patient with interstitial deletion of the short arm of chromosome 3 (pter->p21.2::p12->qter) and a CHARGE-like phenotype. Am J Med Genet 1997; 69: 413-417.

15 Hartshorne TS, Stratton KK, van Ravenswaaij-Arts CMA: Prevalence of genetic testing in CHARGE syndrome. J Genet Counsel 2011; 20: 49-57.

16 Forward KE, Cummings EA, Blake KD: Risk factors for poor bone health in adolescents and adults with CHARGE syndrome. Am J Med Genet 2007; 143A: 839-845.

17 Dobbelsteyn C, Peacocke SD, Blake KD, Crist W, Rashid M: Feeding difficulties in children with charge syndrome: prevalence, risk factors, and prognosis. Dysphagia 2008; 23: 127-135.

18 Blake KD, MacCuspie J, Corsten G: Botulinum toxin injections into salivary glands to decrease oral secretions in CHARGE syndrome: prospective case study. Am J Med Genet 2012; 158A: 828-831.

19 Trider CL, Corsten G, Morrison D, Hefner M, Davenport S, Blake K: Understanding obstructive sleep apnea in ahildren with CHARGE syndrome. Int J Pediatr Otorhinolaryngol 2012; 76: 947-953.

20 Bergman JEH, Bocca G, Hoefsloot LH, Meiners LC, van Ravenswaaij-Arts CMA: Anosmia predicts hypogonadotropic hypogonadism in CHARGE syndrome. J Pediatr 2011; 158: 474-479. 